\title{
A novel $R A B 39 B$ mutation and concurrent de novo NF1 mutation in a boy with neurofibromatosis type 1, intellectual disability, and autism: a case report
}

Claudia Santoro ${ }^{1,2}$, Teresa Giugliano ${ }^{3}$, Pia Bernardo ${ }^{4}$, Federica Palladino ${ }^{2}$, Annalaura Torella $^{3}$, Francesca del Vecchio Blanco ${ }^{3}$, Maria Elena Onore ${ }^{3}$, Marco Carotenuto', Vincenzo Nigro ${ }^{3,5}$ and Giulio Piluso ${ }^{3^{*}}$ (D)

\begin{abstract}
Background: Mutations in RAB39B at Xq28 causes a rare form of X-linked intellectual disability (ID) and Parkinson's disease. Neurofibromatosis type 1 (NF1) is caused by heterozygous mutations in NF1 occurring de novo in about $50 \%$ of cases, usually due to paternal gonadal mutations. This case report describes clinical and genetic findings in a boy with the occurrence of two distinct causative mutations in NF1 and RAB39B explaining the observed phenotype.

Case presentation: Here we report a 7-year-old boy with multiple café-au-lait macules (CALMs) and freckling, severe macrocephaly, peculiar facial gestalt, severe ID with absent speech, epilepsy, autistic traits, self-harming, and aggressiveness. Proband is an only child born to a father aged 47. Parents did not present signs of NF1, while a maternal uncle showed severe ID, epilepsy, and tremors.By RNA analysis of NF1, we identified a de novo splicing variant (NM_000267.3:C.6579+2T>C) in proband, which explained NF1 clinical features but not the severe ID, behavioral problems, and aggressiveness. Family history suggested an X-linked condition and massively parallel sequencing of X-exome identified a novel RAB39B mutation (NM_171998.2:c.436_447del) in proband, his mother, and affected maternal uncle, subsequently validated by Sanger sequencing in these and other family members. Conclusions: The case presented here highlights how concurrent genetic defects should be considered in NF1 patients when NF1 mutations cannot reasonably explain all the observed clinical features.
\end{abstract}

Keywords: Neurofibromatosis type 1, RAB39B, X-linked intellectual disability, Autism, Parkinson's disease, Case report

\section{Background}

Mutations in $R A B 39 B$ (MIM 300774) at Xq28 cause a syndromic form of X-linked intellectual disability (XLID), with very few affected males described to date (MRX72; MIM 300271) [1-3].

\footnotetext{
* Correspondence: giulio.piluso@unicampania.it

${ }^{3}$ Department of Precision Medicine, University of Campania "Luigi Vanvitelli", Via Luigi De Crecchio,7 -, 80138 Naples, Italy

Full list of author information is available at the end of the article
}

Affected patients present variable neurological features, including moderate to severe ID, seizures, autism spectrum disorder (ASD), macrocephaly, delayed psychomotor development, and early-onset Parkinson's disease, as in the allelic Waisman syndrome (WSMN; OMIM 311510) [2].

In mouse brain, Rab39b is expressed in cortical and hippocampal neurons, as well as in dopaminergic neurons of the substantia nigra, concordant with its association with parkinsonism and cognitive impairment

(c) The Author(s). 2020 Open Access This article is licensed under a Creative Commons Attribution 4.0 International License, which permits use, sharing, adaptation, distribution and reproduction in any medium or format, as long as you give appropriate credit to the original author(s) and the source, provide a link to the Creative Commons licence, and indicate if changes were made. The images or other third party material in this article are included in the article's Creative Commons licence, unless indicated otherwise in a credit line to the material. If material is not included in the article's Creative Commons licence and your intended use is not permitted by statutory regulation or exceeds the permitted use, you will need to obtain permission directly from the copyright holder. To view a copy of this licence, visit http://creativecommons.org/licenses/by/4.0/ The Creative Commons Public Domain Dedication waiver (http://creativecommons.org/publicdomain/zero/1.0/) applies to the data made available in this article, unless otherwise stated in a credit line to the data. 
in humans [4]. Rab39b knockout mice showed reduced cortical neurogenesis, macrocephaly, and autistic behaviors, similarly to patients with mutations in $R A B 39 B$ [5]. The Ras-related protein Rab-39B is a small neuronspecific GTPase that contributes to synapse formation and maintenance by regulating organization and dynamics of intracellular membranes and vesicular membrane traffic [6]. With its effector, the protein interacting with C-kinase 1, Rab-39B regulates availability of AMPA receptor, important for synaptic plasticity [7]. Furthermore, the complex formed by C9orf72, WDR41, and SMCR8 was found to act as a GDP/GTP exchange factor for Rab-8A and Rab-39B, suggesting that Rab-39B might be involved in autophagy regulation [8]. However, precisely how $R A B 39 B$ loss-of-function or increased dosage [9] can perturb neuronal development leading to cognitive impairment needs further clarification.

Neurofibromatosis type 1 (NF1; MIM 162200) is caused by dominantly inherited mutations in NF1 (MIM 613113), a complex gene encoding for neurofibromin, a GTPase-activating protein that negatively regulates Ras/ MAPK signaling pathway [10]. In about $50 \%$ of cases, mutations occur de novo, with NF1 exhibiting one of the highest single locus mutation rates known in humans $\left(1 \times 10^{-4}\right.$ per gamete per generation) [11]. De novo mutations are mainly linked to paternal age and to the increasing number of cell divisions in the male germ line [12].

Here, we describe a boy with clinical diagnosis of NF1 complicated by severe macrocephaly, dysmorphic features, severe ID with absent speech, epilepsy, and ASD. Based on his family history, these neurological features could not be only assigned to NF1 and an extensive genetic characterization was carried out. To our knowledge, this is the first case in which two distinct causative mutations in NF1 and $R A B 39 B$ explained the observed phenotype.

\section{Case presentation}

We report the clinical and genetic characterization of a boy (III.1; Fig. 1), the only child of apparently healthy parents, who was referred to our NF1 Referral Center at age 7 due to the presence of CALMs and freckling.

Proband was born at week 39 of an uneventful pregnancy by $\mathrm{C}$-section because of neonatal macrosomia. Prenatal karyotyping was normal $(46, \mathrm{XY})$. At birth, weight was $3.930 \mathrm{~kg}$ (75th centile), length $52 \mathrm{~cm}$ (75th centile), and head circumference $35 \mathrm{~cm}$ (66th centile). The child presented respiratory distress not requiring intubation. He started walking at 2 years and spoke his first words at 12 months, with reported regression and loss of verbal competence soon after.

Severe ID and ASD was diagnosed at age 3, and pharmacologically treated with risperidone. At this age, he had his first episode of generalized seizures during fever, followed by others while awake and in apyrexia. A sleep electroencephalogram showed rare physiological figures, as sleep spindles and k complex, and epileptiform abnormalities in the right temporal region. Seizures were adequately controlled by levetiracetam. Brain magnetic resonance imaging performed at age 4 showed periventricular white matter hyperintensities, likely due to hypoxia, and revealed T2W hyperintensities in basal ganglia bilaterally, while FLAIR images showed hippocampal and temporomesial hyperintensities bilaterally. Ophthalmological evaluation, electrocardiogram, auditory/visual brainstem potentials were normal. $\mathrm{He}$ showed hyperactivity and motor instability, as well as limited social interactions and aggressiveness. At age 6, sleep disorder (insomnia) was observed and chlorpromazine, clonazepam, and melatonin were added to the pharmacological therapy.

At our first consultation, family history revealed that a maternal uncle (II.4; Fig. 1) was also affected by severe ID, absence of speech, and tremors, with global motor impairment. He had been institutionalized for many years and while this study was ongoing died suddenly at the age of 53 from complications of a pulmonary infection, preventing any further clinical examination. Proband was still able to walk, and epilepsy and sleep disorders were well managed pharmacologically. Global motor impairment, severe behavioral disorders, including self-injurious behavior and psychomotor agitation episodes, and food selectivity were noted. At medical examination, he presented with CALMs and freckling, suggestive of NF1 according to $\mathrm{NIH}$ diagnostic criteria [10]. He presented restless with absent speech (less than 5 words), macrocephaly (head circumference $56 \mathrm{~cm},>+2 \mathrm{SD}$ ), peculiar facial gestalt, gingival hypertrophy, and generalized hypotonia. Previously performed array-CGH and genetic testing for fragile $\mathrm{X}$ syndrome resulted negative.

At last observation, at age 14, his pharmacological therapy included the oral administration of risperidone (0.75 mg BID), levetiracetam (250 mg BID), lorazepam (6 drops BID), clonazepam (12 drops BID) and sodium valproate $(250 \mathrm{mg}$ TID), with a moderate control of both seizures and behavioral problems.

Based on clinical signs of NF1 and family history suggestive of an XLID, despite suspicion of neonatal hypoxia, a comprehensive genetic investigation was performed. As the legal representative of a minor, proband's mother gave written informed consent to the study.

RNA analysis (see "Supplemental Information") [13] revealed skipping of exon 43 in NF1 transcript (not shown) due to a de novo heterozygous splicing variant at genomic level [NM_000267.3:c.6579+2T>C; p.(Glu 

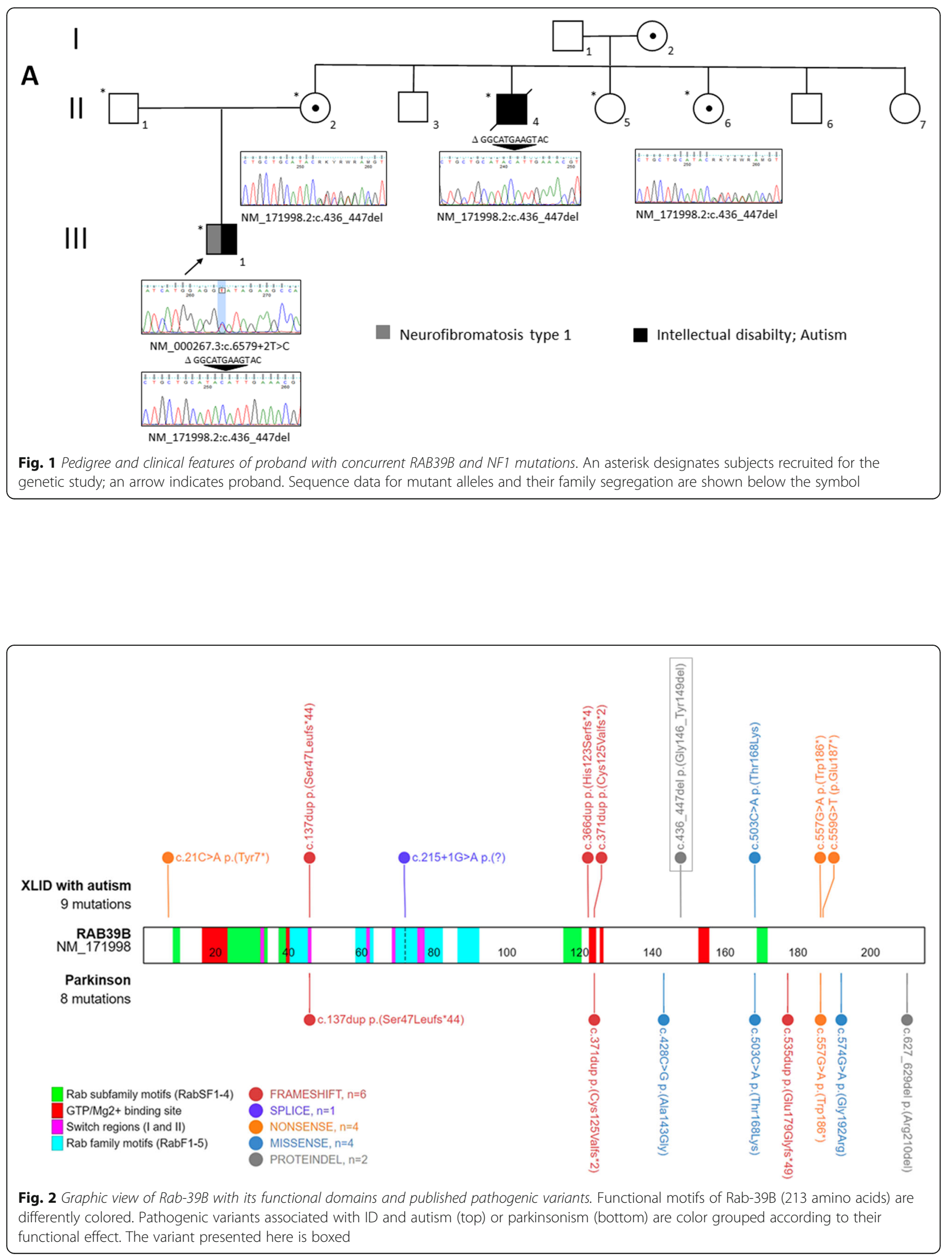
2122Glyfs"27)] (Fig. 1). X-exome sequencing was then performed on proband, his mother, and affected maternal uncle (see "Supplemental Information") [14]. We identified a novel $R A B 39 B$ mutation (NM_171998.3: c.436_447del) (Fig. 1). This in-frame deletion removed four amino acids (p.Gly146_Tyr149del) in the Cterminus region of Ras-related protein Rab-39B. Segregation analysis in family members was in line with $\mathrm{X}$-linked inheritance and one (II.6) of two maternal aunts participating in the study resulted a carrier (Fig. 1 ). As unbalanced $X$ inactivation is reported in females, $[2,3,15]$ proband's mother and maternal aunts were further investigated, highlighting preferential inactivation of the mutant allele in carrier females (II.2 66\%:34\% and II.6 73\%:27\%, respectively).

\section{Discussion and conclusions}

Cognitive impairment commonly affects children with NF1 and includes an IQ in the low average range, learning difficulties and social dysfunction [16, 17]. ID was reported for NF1 patients carrying a 17q11.2 microdeletion, [18] while ASD features were observed in up to $30 \%$ of children with NF1 and epilepsy in about $4 \%$ of NF1 patients [19, 20].

We identified a de novo heterozygous mutation in NF1 that affects splicing and was not related to a specific NF1 phenotype or to an impaired cognitive profile [13]. Severe ID with absent speech, associated with epilepsy, ASD, self-injurious behavior, and aggressiveness, could not be explained by the NF1 mutation alone. Although brain imaging showed signs of hypoxia, family history
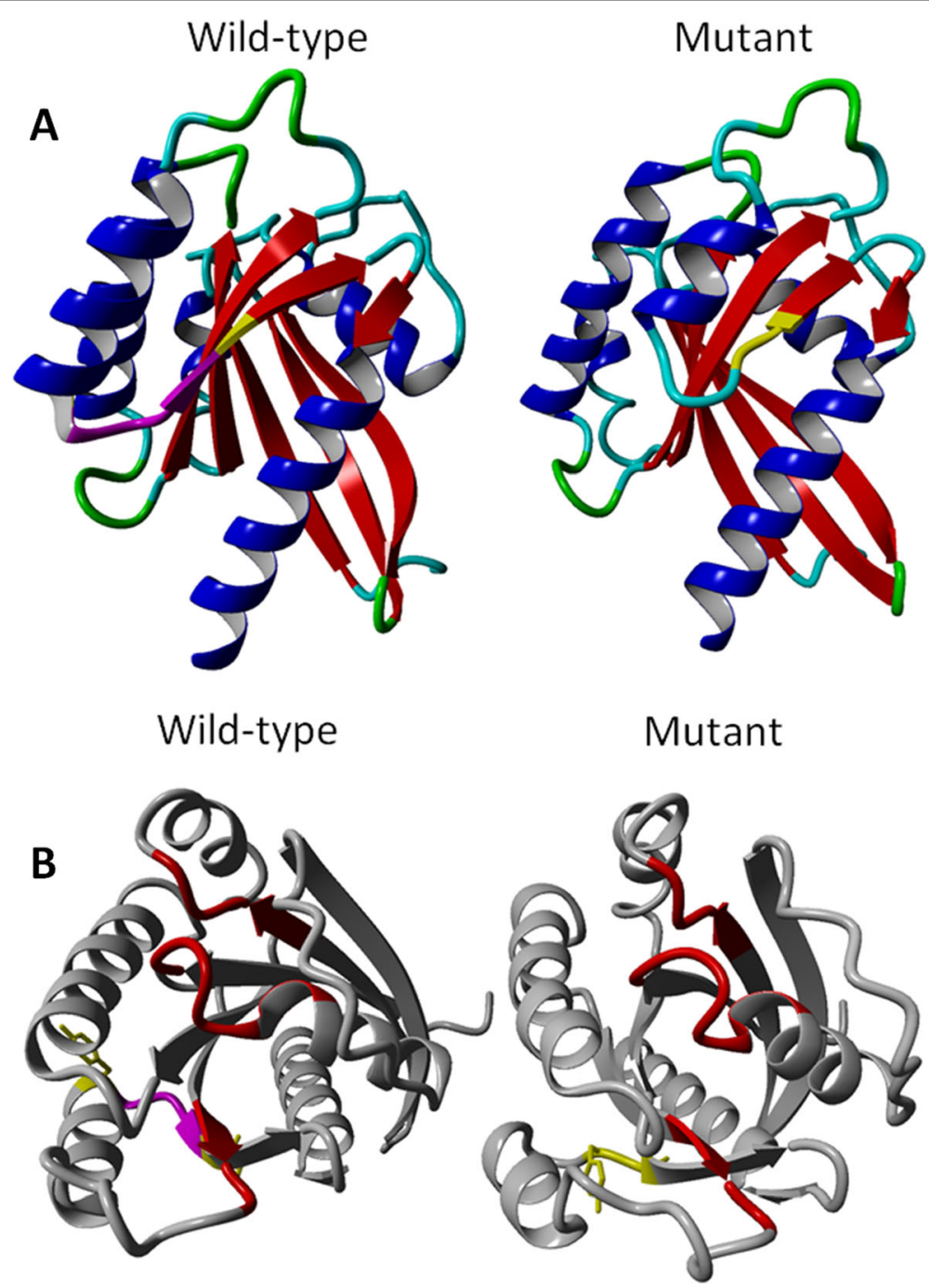

Fig. 3 3D homology modeling. The 3D homology model (RefSeq: NP_741995.1; residues 1-213) was generated based on the available Rab-8A model (RCS-PDB: 5SZl; residues 1-209) for wild-type and mutant form. a Deleted residues (GMKY) are highlighted in magenta, and flanking residues $\left(Y^{145} ; I^{150}\right)$ in yellow. $\mathbf{b}$ The GTP/Mg2+ binding site is highlighted in red 
suggested the existence of an additional genetic condition, likely linked to $\mathrm{X}$-chromosome.

A novel RAB39B mutation (NM_171998.3:c.436_ $447 \mathrm{del}$ ) was subsequently identified in proband, his carrier mother, and affected maternal uncle, as well as in one maternal aunt (Fig. 1). This in-frame deletion removed four amino acids (p.Gly146_Tyr149del) in the C-terminus region of Rab-39B. To date, only 12 causative variants were reported in $R A B 39 B$, mainly associated with variable ID, macrocephaly, and ASD, and in some cases complicated by early-onset Parkinson's disease (Fig. 2) [1-3, 15, 21-23].

As other Ras-related GTPases, Rab proteins have six $\beta$-sheets and two Switch elements (I and II) that change conformation upon nucleotide binding (Fig. 2) [24]. They also present five specific Rab family (F1-5) and four Rab subfamily (SF1-4) motifs (Fig. 2) [24]. Threedimensional homology modeling [25] based on the available Ras-related protein Rab-8A model (RCS-PDB: 5SZI) showed that the mutant protein lost part of the sixth $\beta$ sheet and the nearby $\alpha$-helix compared to wild-type (Fig. 3a). GTP $/ \mathrm{Mg}^{2+}$ binding site conformation also seemed to be affected (Fig. 3b) [26].

The mutation identified in $R A B 39 B$ explained neurocognitive and neurological features observed in affected male family members, while the unbalanced $\mathrm{X}$ inactivation in carrier females was in agreement with their apparently healthy status. The independent occurrence of a de novo NF1 mutation accounted for NF1 signs and could contribute to the severity of neurocognitive features.

In NF1, severe cognitive impairment not linked to a 17q11.2 microdeletion syndrome or not explainable by other causes should not exclude the albeit rare possibility of another concomitant genetic condition. The high mutation rate of NF1 and the relatively not low worldwide prevalence of neurofibromatosis type 1 , can explain the occurrence with NF1 of distinct genetic condition in the same patient [27-30]. This case report clearly underscores the need for more extensive genetic investigation, today possible thanks to massive clinical application of next-generation sequencing-based genetic testing, when the identification of a causative mutation does not fully explain the observed phenotype.

\section{Supplementary information}

Supplementary information accompanies this paper at https://doi.org/10. 1186/s12883-020-01911-0.

Additional file 1.

\section{Abbreviations}

AMPA: a-amino-3-hydroxy-5-methyl-4-isoxazolepropionic acid; ASD: Autism spectrum disorder; BID: Twice a day; CALMs: Café-au-lait macules; FLAIR: Fluid attenuation inversion recovery; ID: Intellectual disability;
NF1: Neurofibromatosis type 1; RAB39B: Gene encoding Ras-related protein Rab-39B; Ras/MAPK: Ras/mitogen activated protein kinase; TID: Three times a day; XLID: X-linked intellectual disability

\section{Acknowledgements}

The authors thank patients for their willingness to participate in this study. We thank Catherine Fisher for the English language revision.

\section{Authors' contributions}

CS, TG and GP contributed to the concept, drafting, and reporting of the case. AT, FDVB and MEO contributed to the genetic investigation and data validation. PB, FP and MC contributed to neuropsychiatric evaluation of the case. VN and GP contributed to the final revision of the manuscript. All authors have read and approved the final manuscript.

\section{Funding}

No financial assistance was received in support of the study.

\section{Availability of data and materials}

All data generated or analyzed during this study are included in this published article.

\section{Ethics approval and consent to participate}

Approved by the Ethics Committee of the University of Campania "Luigi Vanvitelli". As the legal representative of a minor, proband's mother gave written informed consent to the study.

\section{Consent for publication}

As the legal representative of a minor, proband's mother gave written informed consent to the publication and to the photographs.

\section{Competing interests}

The authors declare that they have no competing interests.

\section{Author details}

${ }^{1}$ Department of Physical and Mental Health, and Preventive Medicine, University of Campania "Luigi Vanvitelli", Naples, Italy. ${ }^{2}$ Department of Women, Children, and General and Specialized Surgery, University of Campania "Luigi Vanvitelli", Naples, Italy. ${ }^{3}$ Department of Precision Medicine, University of Campania "Luigi Vanvitelli", Via Luigi De Crecchio,7 -, 80138 Naples, Italy. ${ }^{4}$ Department of Neurosciences, Pediatric Hospital Santobono-Pausilipon, Naples, Italy. ${ }^{5}$ Telethon Institute of Genetics and Medicine (TIGEM), Pozzuoli, Italy.

Received: 3 July 2020 Accepted: 26 August 2020

Published online: 01 September 2020

\section{References}

1. Giannandrea M, Bianchi V, Mignogna ML, Sirri A, Carrabino S, D'Elia E, et al. Mutations in the small GTPase gene RAB39B are responsible for X-linked mental retardation associated with autism, epilepsy, and macrocephaly. Am J Hum Genet. 2010;86(2):185-95. https://doi.org/10.1016/j.ajhg.2010.01.011.

2. Wilson GR, Sim JC, McLean C, Giannandrea M, Galea CA, Riseley JR, et al. Mutations in RAB39B cause X-linked intellectual disability and early-onset Parkinson disease with alpha-synuclein pathology. Am J Hum Genet. 2014; 95(6):729-35. https://doi.org/10.1016/j.ajhg.2014.10.015.

3. Woodbury-Smith M, Deneault E, Yuen RKC, Walker S, Zarrei M, Pellecchia G, et al. Mutations in RAB39B in individuals with intellectual disability, autism spectrum disorder, and macrocephaly. Mol Autism. 2017;8:59. https://doi. org/10.1186/s13229-017-0175-3.

4. Gao Y, Wilson GR, Stephenson SEM, Oulad-Abdelghani M, CharletBerguerand N, Bozaoglu K, et al. Distribution of Parkinson's disease associated RAB39B in mouse brain tissue. Mol Brain. 2020;13(1):-52. https:// doi.org/10.1186/s13041-020-00584-7.

5. Zhang W, Ma L, Yang M, Shao Q, Xu J, Lu Z, et al. Cerebral organoid and mouse models reveal a RAB39b-PI3K-mTOR pathway-dependent dysregulation of cortical development leading to macrocephaly/autism phenotypes. Genes Dev. 2020;34(7-8):580-97. https://doi.org/10.1101/gad. 332494.119 . 
6. Mignogna ML, D'Adamo P. Critical importance of RAB proteins for synaptic function. Small GTPases. 2018;9(1-2):145-57. https://doi.org/10.1080/ 21541248.2016.1277001.

7. Mignogna ML, Giannandrea M, Gurgone A, Fanelli F, Raimondi F, Mapelli L, et al. The intellectual disability protein RAB39B selectively regulates GluA2 trafficking to determine synaptic AMPAR composition. Nat Commun. 2015;6: 6504. https://doi.org/10.1038/ncomms7504.

8. Sellier C, Campanari ML, Julie Corbier C, Gaucherot A, Kolb-Cheynel I, OuladAbdelghani M, et al. Loss of C9ORF72 impairs autophagy and synergizes with polyQ Ataxin-2 to induce motor neuron dysfunction and cell death. EMBO J. 2016;35(12):1276-97. https://doi.org/10.15252/embj.201593350.

9. Vanmarsenille L, Giannandrea M, Fieremans N, Verbeeck J, Belet S, Raynaud $M$, et al. Increased dosage of RAB39B affects neuronal development and could explain the cognitive impairment in male patients with distal Xq28 copy number gains. Hum Mutat. 2014;35(3):377-83. https://doi.org/10.1002/ humu.22497.

10. Friedman JM. Neurofibromatosis 1. In: Adam MP, Ardinger HH, Pagon RA, Wallace SE, LJH B, Stephens K, et al., editors. GeneReviews((R)). Seattle: University of Washington; 1993-2020.

11. Friedman JM. Epidemiology of neurofibromatosis type 1. Am J Med Genet. 1999:89(1):1-6.

12. Rahbari R, Wuster A, Lindsay SJ, Hardwick RJ, Alexandrov LB, Turki SA, et al. Timing, rates and spectra of human germline mutation. Nat Genet. 2016; 48(2):126-33. https://doi.org/10.1038/ng.3469.

13. Giugliano T, Santoro C, Torella A, Del Vecchio BF, Grandone A, Onore ME, et al. Clinical and genetic findings in children with Neurofibromatosis type 1, Legius syndrome, and other related Neurocutaneous disorders. Genes. 2019;10:8. https://doi.org/10.3390/genes10080580.

14. Giugliano T, Santoro C, Torella A, Del Vecchio BF, Bernardo P, Nigro V, et al. UBE2A deficiency in two siblings: a novel splicing variant inherited from a maternal germline mosaicism. Am J Med Genet A. 2018;176(3):722-6. https://doi.org/10.1002/ajmg.a.38589.

15. Mata IF, Jang Y, Kim CH, Hanna DS, Dorschner MO, Samii A, et al. The RAB39B p.G192R mutation causes X-linked dominant Parkinson's disease. Mol Neurodegener. 2015;10:50. https://doi.org/10.1186/s13024-015-0045-4.

16. Chisholm AK, Anderson VA, Pride NA, Malarbi S, North KN, Payne JM. Social function and autism Spectrum disorder in children and adults with Neurofibromatosis type 1: a systematic review and meta-analysis. Neuropsychol Rev. 2018;28(3):317-40. https://doi.org/10.1007/s11065-0189380-x.

17. Bergqvist $C$, Servy A, Valeyrie-Allanore L, Ferkal S, Combemale $P$, Wolkenstein $\mathrm{P}$, et al. Neurofibromatosis 1 French national guidelines based on an extensive literature review since 1966. Orphan J Rare Dis. 2020;15(1): 37. https://doi.org/10.1186/s13023-020-1310-3.

18. Kehrer-Sawatzki H, Mautner VF, Cooper DN. Emerging genotype-phenotype relationships in patients with large NF1 deletions. Hum Genet. 2017;136(4): 349-76. https://doi.org/10.1007/s00439-017-1766-y.

19. Garg S, Plasschaert E, Descheemaeker MJ, Huson S, Borghgraef M, Vogels A, et al. Autism spectrum disorder profile in neurofibromatosis type I. J Autism Dev Disord. 2015;45(6):1649-57. https://doi.org/10.1007/s10803-014-2321-5.

20. Santoro C, Bernardo P, Coppola A, Pugliese U, Cirillo M, Giugliano T, et al. Seizures in children with neurofibromatosis type 1 : is neurofibromatosis type 1 enough? Ital J Pediatr. 2018;44(1):41. https://doi.org/10.1186/s13052018-0477-x.

21. Hu H, Haas SA, Chelly J, Van Esch H, Raynaud M, de Brouwer AP, et al. Xexome sequencing of 405 unresolved families identifies seven novel intellectual disability genes. Mol Psychiatry. 2016;21(1):133-48. https://doi. org/10.1038/mp.2014.193.

22. Shi $\mathrm{CH}$, Zhang SY, Yang ZH, Yang J, Shang DD, Mao CY, et al. A novel RAB39B gene mutation in X-linked juvenile parkinsonism with basal ganglia calcification. Mov Disord. 2016;31(12):1905-9. https://doi.org/10.1002/mds. 26828.

23. Ciammola A, Carrera P, Di Fonzo A, Sassone J, Villa R, Poletti B, et al. Xlinked parkinsonism with intellectual disability caused by novel mutations and somatic mosaicism in RAB39B gene. Parkinsonism Relat Disord. 2017;44: 142-6. https://doi.org/10.1016/j.parkreldis.2017.08.021.

24. Pfeffer SR. Structural clues to Rab GTPase functional diversity. J Biol Chem. 2005:280(16):15485-8. https://doi.org/10.1074/jbc.R500003200.

25. Waterhouse A, Bertoni M, Bienert S, Studer G, Tauriello G, Gumienny R, et al. SWISS-MODEL: homology modelling of protein structures and complexes.
Nucleic Acids Res. 2018;46(W1):W296-303. https://doi.org/10.1093/nar/ gky427.

26. Khan AR, Menetrey J. Structural biology of Arf and Rab GTPases' effector recruitment and specificity. Structure. 2013;21(8):1284-97. https://doi.org/10. 1016/j.str.2013.06.016.

27. Yilmaz H, Erkin G, Gumus H, Nalbant L. Coexistence of Neurofibromatosis Type-1 and MTHFR C677T gene mutation in a young stroke patient: a case report. Case Rep Neurol Med. 2013;2013:735419. https://doi.org/10.1155/ 2013/735419.

28. Lin X, Chen H, Zhu W, Lian S. Neurofibromatosis type 1 and X-linked ichthyosis in a patient with a novel frameshift mutation in the NF1 gene. Eur J Dermatol. 2016;26(5):498-9. https://doi.org/10.1684/ejd.2016.2830.

29. Altay D, Gorukmez O, Arslan D. Coexistence of three different mutations in a male infant: neurofibromatosis type 1, progressive familial intrahepatic cholestasis type 2 and LPIN3. Fetal Pediatr Pathol. 2020:1-6. https://doi.org/ 10.1080/15513815.2020.1783405.

30. Thiel C, Wilken M, Zenker M, Sticht H, Fahsold R, Gusek-Schneider GC, et al. Independent NF1 and PTPN11 mutations in a family with neurofibromatosis-Noonan syndrome. Am J Med Genet A. 2009;149A(6): 1263-7. https://doi.org/10.1002/ajmg.a.32837.

\section{Publisher's Note}

Springer Nature remains neutral with regard to jurisdictional claims in published maps and institutional affiliations.
Ready to submit your research? Choose BMC and benefit from:

- fast, convenient online submission

- thorough peer review by experienced researchers in your field

- rapid publication on acceptance

- support for research data, including large and complex data types

- gold Open Access which fosters wider collaboration and increased citations

- maximum visibility for your research: over $100 \mathrm{M}$ website views per year

At BMC, research is always in progress.

Learn more biomedcentral.com/submissions 